\title{
$n-6$ and $n-3$ Essential fatty acids in rheumatoid arthritis and other rheumatic conditions
}

\author{
J. J. F. Belch* and A. Muir \\ University Department of Medicine, Ninewells Hospital \& Medical School, Dundee DD1 9SY, UK
}

\section{Essential fatty acid metabolism}

The essential fatty acids (EFA) have unique roles as precursor molecules of chemical regulators of inflammatory and immune cell function (Belch, 1989). These are the leukotrienes (LT) and the prostaglandins (PG). These compounds are synthesized and released by almost every tissue in the body, and participate in many biological functions, including the inflammatory and immune processes. Most work has focused on arachidonic acid, the precursor of the 2-series PG and the 4-series LT. Altering the EFA content in the diet or administering different EFA as supplements can modify the production of the various PG and LT by altering the substrate EFA. For example, the ingestion of a diet rich in borage (Borago officinalis) oil (Starflower Oil) or evening primrose (Oenothera biennis) oil (EPO) will elevate levels of dihomo- $\gamma$-linolenic acid, which will result in an increase in the 1-series PG, e.g. PGE 1 (Manku et al. 1986). In common with all $\mathrm{PG}, \mathrm{PGE}_{1}$ is able to induce the cardinal signs of inflammation, i.e. redness, oedema, pain, heat and loss of function. In contrast, however, the action of $\mathrm{PGE}_{1}$ on the inflammatory cells, the polymorphonuclear leucocytes, is mostly inhibitory (Weissmann et al. 1980). PGE $_{1}$ increases intracellular cAMP and it is this increase in polymorphonuclear cell cAMP which decreases the release of lysosomal enzymes, decreases polymorphonuclear cell chemotaxis and the margination and adherence of leucocytes in the blood vessels. Similarly, the effect of $\mathrm{PGE}_{1}$ on the lymphocyte is thought to be inhibitory (Rogers, 1985). Exogenous addition of $\mathrm{PGE}_{1}$ inhibits both in vitro function of lymphocytes and in vivo responses mediated by lymphocytes. It has been suggested that $\mathrm{PGE}_{1}$ has a negative feedback role in chronic inflammation, initially aiding development of the cardinal signs of inflammation followed by a later suppressant effect, and this anti-inflammatory effect might be useful in a disease characterized by inflammation, such as rheumatoid arthritis (RA; Fig. 1).

A further benefit of a diet rich in compounds containing $\gamma$-linolenic acid (GLA; which will be metabolized to dihomo- $\gamma$-linolenic acid) is the inhibitory effect on LT synthesis. Dihomo- $\gamma$-linolenic acid cannot itself be converted to LT, but can form a 15-hydroxyl derivative that blocks transformation of arachidonic acid to LT (Voorlees, 1983). Additionally, there may be formation of a 13-hydroxyoctadecadienoic acid product which may also have anti-inflammatory effects. Thus, increasing GLA intake will allow its metabolism to dihomo- $\gamma$-linolenic acid, when it will act as a competitive inhibitor of the 2-series PG and 4-series LT and thus potentially suppress inflammation (Jantti et al. 1989; Oxholm et al. 1992).

In the same way it is postulated that eicosapentaenoic acid (EPA) is metabolized to the less-potent (in terms of inflammation) PG of the 3-series and 5-series LT (Prescott et al. 1985). Fish oil contains EPA and docosahexaenoic acid, both of which have been shown to modulate immune function. Studies of normal volunteers ingesting high concentrations of EPA confirm a shift of neutrophil production away from $\mathrm{LTB}_{4}$ towards $\mathrm{LTB}_{5}$ (Prescott et al. 1985). EPA also inhibits the polymorphonuclear cell chemotaxis.

\section{Neutrophil adhesion}

The leucocyte flows in the central area of the bloodstream. On activation, it marginates to the side of the blood vessel (Fig. 2). It then rolls along the blood vessel until it is immobilized. After immobilization, it passes through the endothelium into the tissues where it can mediate the inflammatory response. The ability of the polymorphonuclear cells to roll on and adhere to the endothelium is mediated by various cell-adhesion molecules. In a preliminary pilot study (Maple et al. 1998), we evaluated the effect of GLA on leucocyte

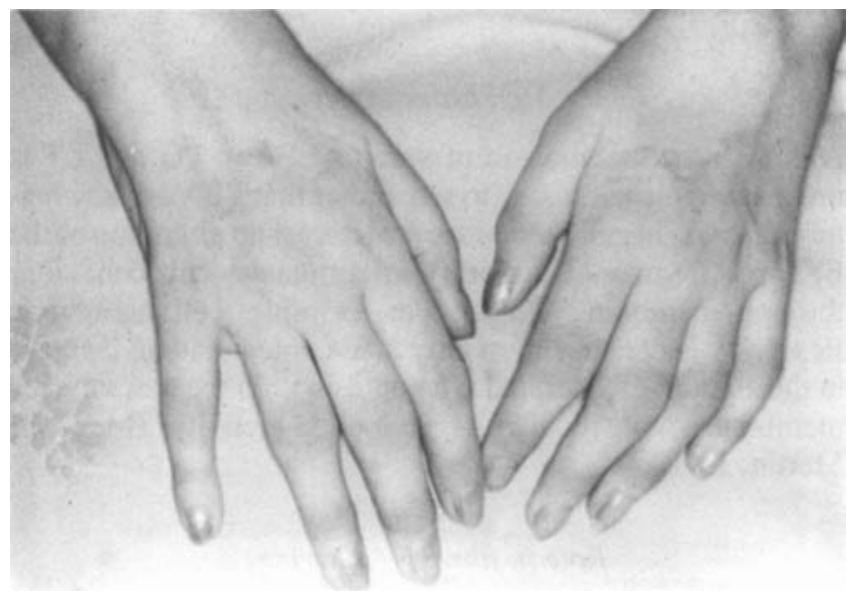

Fig. 1. Swelling in rheumatoid joints.

\footnotetext{
Abbreviations: EFA, essential fatty acids; EPA, eicosapentaenoic acid; EPO, evening primrose oil; GLA, $\gamma$-linolenic acid; LT, leukotrienes; PG, prostaglandins; RA, rheumatoid arthritis.

*Corresponding author: Professor J. J. F. Belch, fax +44 (0)1382 660675, email JJFBELCH@Ninewells.dundee.ac.uk
} 


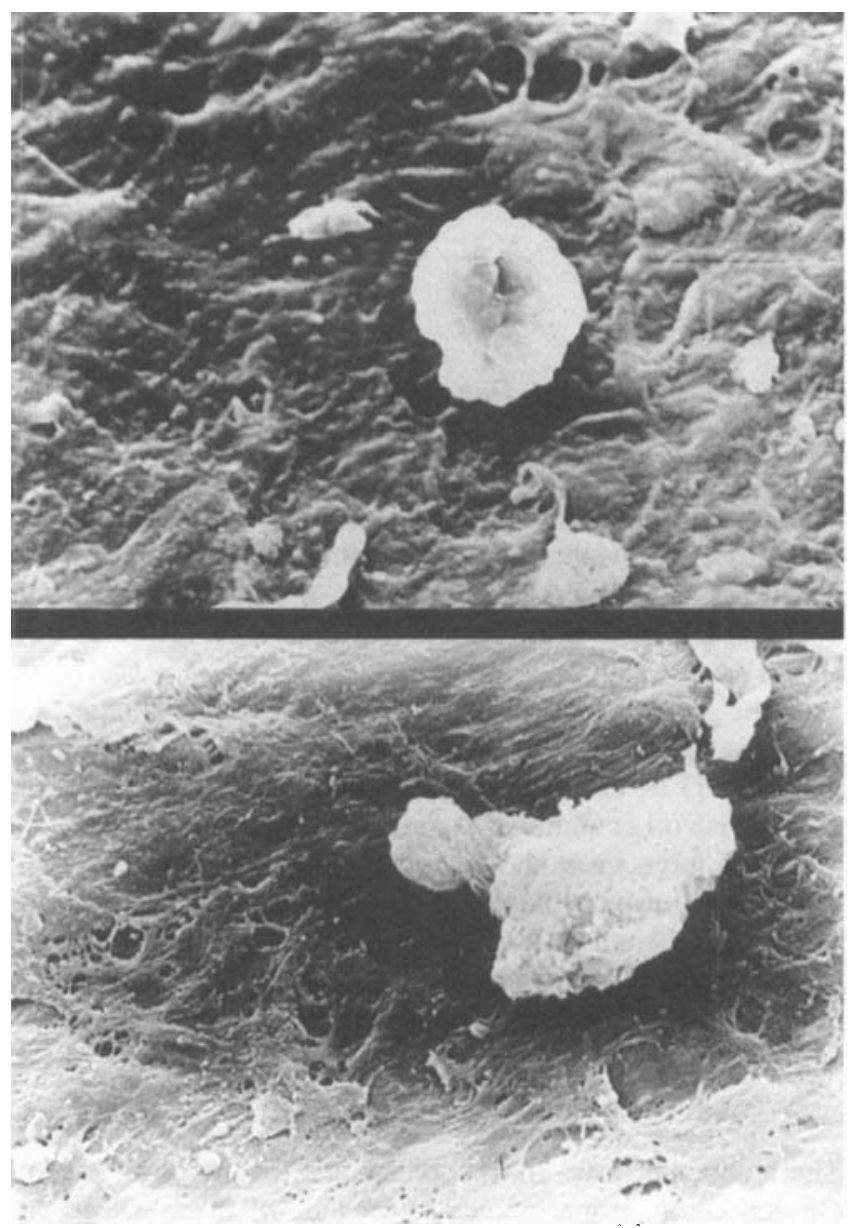

Fig. 2. The leucocyte before and after stimulation by $\mathrm{N}$-formylmethionyl-leucyl-phenylalanine, showing adhesion to the endothelium following activation.

aggregation in whole blood in response to $\mathrm{N}$-formylmethionyl-leucyl-phenylalanine and found that leucocyte aggregation was reduced by the 12 -week GLA treatment period. A larger study is underway to investigate the effect on cell adhesion molecules.

\section{Membrane effects}

Although the metabolism of various EFA to PG and LT is important, it is necessary to remember that EFA are key features, per se, in cell membrane structure, and alteration of the EFA profile may also modify inflammatory-cell behaviour through membrane effects. For example, cell membrane flexibility is dependent on fatty acid content and an increase in the amount of saturated fatty acids within the macrophage membrane will reduce its endocytic activity (Mead \& Mertin, 1978).

\section{Role in fibrosis (scarring)}

Another potential mechanism whereby $n-6$ and $n-3$ fatty acids mediate their beneficial effect is through the fibrinolytic process. Fibrin is deposited in excess in the rheumatoid joint, and an inhibition of the fibrinolytic process has been shown in these patients (McLaren et al. 1990). In a group of subjects with Raynaud's phenomenon secondary to rheumatological conditions, we have shown that a 12 -week course of supplementation of GLA will enhance fibrinolysis through an increase in tissue plasminogen activator, resulting in increased fibrin degradation products occurring in the blood.

In summary, manipulation of the parent EFA can modify inflammation in a number of ways. These include altering the production of eicosanoids, membrane effects and their role in fibrosis (scarring). Furthermore, it is important to appreciate that each type of EFA can interfere with the metabolism of the other. An excess of $n-6$ EFA will reduce the metabolism of $\alpha$-linolenic acid, possibly leading to a deficit of its metabolites, including EPA. Similarly, diets rich in $n-3$ EFA are very effective in inhibiting $n-6$ EFA metabolism (Horrobin, 1991).

\section{Rheumatological conditions and essential fatty acid treatment}

Most studies involving EFA supplementation have taken place in patients with RA (Belch, 1988), but two conditions associated with RA have also been studied. These include Sjögren's syndrome and Raynaud's phenomenon. Additionally, another arthritic disorder, psoriatic arthritis, has also been evaluated. All these conditions will be reviewed.

\section{Sjögren's syndrome}

Sjögren's syndrome is a common autoimmune, chronic inflammatory disorder which is often associated with RA (Tziousas \& Moutsopoulos, 1995). GLA has been reported to be reduced in patients with Sjögren's syndrome (Horrobin, 1984) and replacement via treatment with Efamol (Scotia Pharmaceuticals Ltd., Stirling, Scotland) has been attempted. In the first study (Manthorpe et al. 1984), thirty-six patients were evaluated in a randomized, double-blind, cross-over trial. Unfortunately, only a 1-week washout phase was employed, a design that we now know to be inappropriate when evaluating EFA therapy. Nevertheless, the dose was three capsules of Efamol (500 mg capsules containing $90 \mathrm{mg}$ $\mathrm{GLA} / \mathrm{g}$ ) daily and three tablets of Efavit (containing vitamin $\mathrm{C}$, pyridoxine, niacin and $\mathrm{Zn}$ ) twice daily or a placebo. Assessment was by the Schirmer tear test (Hughes, 1994), which is a measurement of tear fluid production, and its improvement represents enhanced tear formation. The Schirmer tear test showed an improvement during treatment with EFA. The second study evaluated twenty-eight patients (Oxholm et al. 1986). On this occasion treatment of Efamol was given for 8 weeks at a dose of six capsules daily. The ocular score (Hughes, 1994), which included evaluation of the Schirmer tear test, improved during Efamol treatment when compared with the pre-trial values, but not when compared with the placebo group. It is interesting to ask why this work has not been taken further. Carried out in the 1980s, there has been plenty of time for larger conclusive studies to have been completed and it is disappointing that this is not the case. In the light of current knowledge, a longer treatment period ( $\geq 6$ months) should be evaluated. However, on the basis of the current evidence, it is not possible to recommend 
this treatment to patients with Sjögren's syndrome until further data become available.

\section{Raynaud's phenomenon}

Raynaud's phenomenon is characterized by digital vasospasm producing the classical triphasic colour change of blanching due to vascular spasm, cyanosis due to deoxygenation of static venous blood, and rubor reflecting the reactive hyperaemia of return of flow (Belch, 1995). In a disease characterized by vascular spasm, production of vasodilatory PG through manipulation of EFA is an attractive hypothesis. Additionally, there is enhanced platelet aggregation (Belch, 1988), decreased erythrocyte deformability (Belch et al. 1985), increased leucocyte aggregation and release (Lau et al. 1992), and diminished fibrinolysis in these patients (Lau et al. 1993a). All these processes might be expected to be ameliorated by supplementation with GLA or EPA-docosahexaenoic acid.

We have studied the effect of twelve capsules of EPO daily on the manifestations of Raynaud's phenomenon (Belch et al. 1996). The dose of twelve capsules daily provided a total dose of $540 \mathrm{mg}$ GLA. Twenty-one patients received a 2 -week course of run-in placebo medication (liquid paraffin), and thereafter eleven received EPO for 8 weeks and ten patients received a placebo. As the weather worsened from autumn to winter, the placebo group experienced significantly more attacks than the EPO group, and these attacks were of much longer duration (Fig. 3). Visual analogue scales assessing the severity of attacks and coldness of the hands improved in the EPO group. Blood tests showed some anti-platelet effect of the drug as expected. Similar findings have been described in a study of fish oil supplementation in Raynaud's phenomenon (Di Giacomo et al. 1989). Disappointingly however, no further work in this area has been published. Although these studies were of a standard type used to assess Raynaud's phenomenon in the 1980s, current requirements would necessitate larger numbers of subjects to be studied over a longer period of time. Once again these studies have not been forthcoming, and thus one cannot conclusively recommend this treatment for patients with Raynaud's phenomenon.

\section{Arthritis associated with psoriasis}

Interest in patients with psoriatic arthritis and treatment with GLA developed following studies of the psoriatic skin disease where some benefit was shown (Ziboh et al. 1986). Additionally, there has been a study published evaluating $n-3$ treatments of psoriatic skin disease and these appeared to have produced benefits (Veale et al. 1994). Disappointingly, in a study of thirty-two patients evaluated in a double-blind, placebo-controlled trial (Veale et al. 1994), no obvious benefits from GLA supplementation could be seen, in particular the articular index (clinical measurement of inflammation based on joint swelling and tenderness) remained the same in both placebo and treatment groups, as did non- steroidal anti-inflammatory drug consumption. It may be, however, that the dosage of twelve capsules daily was not sufficient to produce benefit, as more

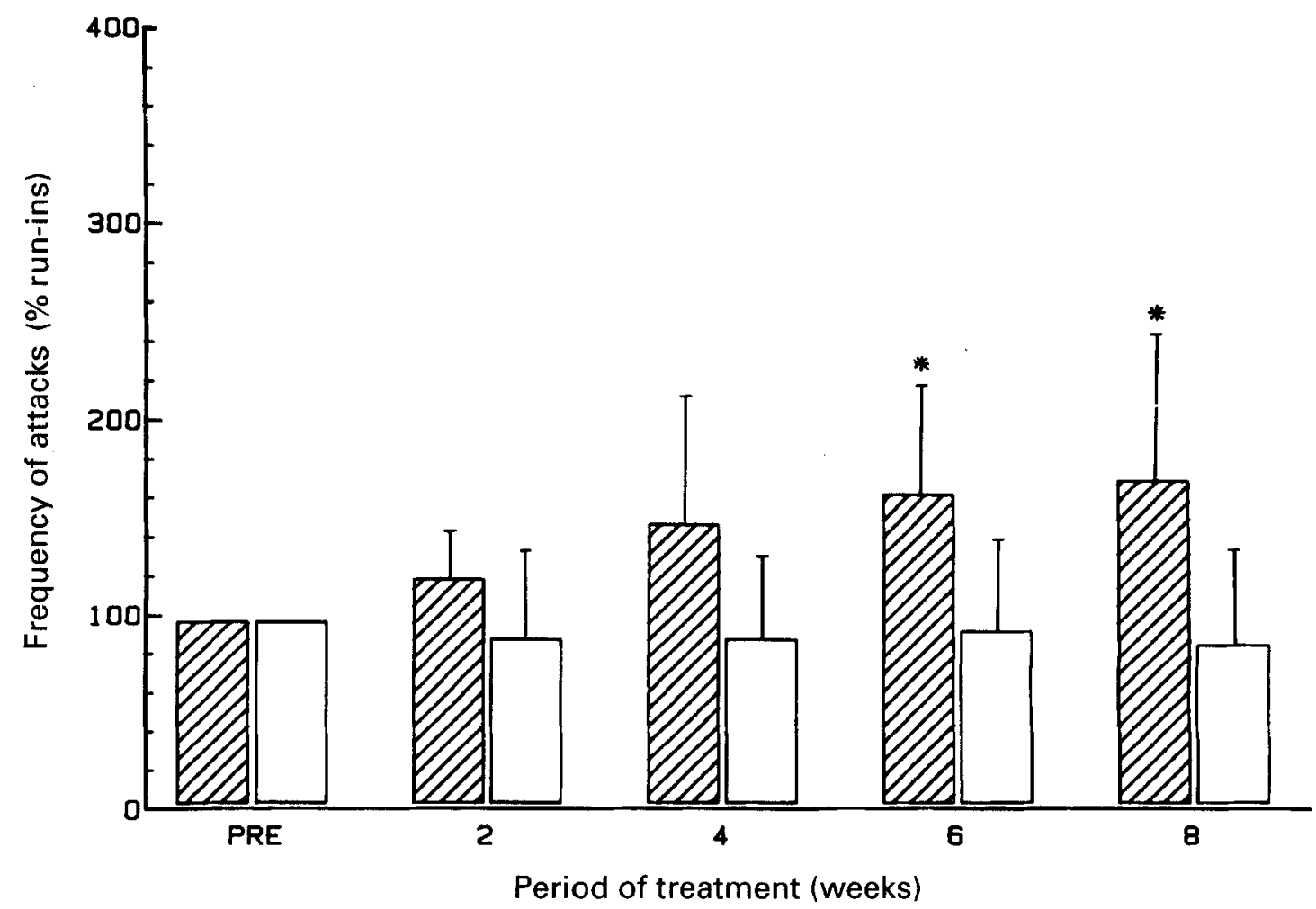

Fig. 3. Frequency of Raynaud's vasospastic attacks in evening primrose (Oenothera biennis) oil-treated ( $\square$ ) and control (wz) groups. Treatment followed a 2-week course of 'run-in' placebo medication (liquid paraffin). Values are means for 2 weeks and standard deviations represent by vertical bars. Mean values were significantly different from those for controls (Mann Whitney): ${ }^{*} P<0.03$. (From Belch et al. 1985b.) 
profound effects in RA are seen at the higher dose (Zurier et al. 1996).

\section{Rheumatoid arthritis}

For the reasons outlined previously, it might be expected that $n-6$ or $n-3$ supplementation or a combination might be useful in this group of patients. The literature, however, is difficult to review because of the tendency for inappropriate study design to be selected for evaluating EFA treatment in RA. This is not necessarily the fault of the investigator(s) concerned, but merely reflects the state of the art as it was when these studies were carried out.

\section{n-6 Essential fatty acids and rheumatoid arthritis}

In one of the first studies (Brown et al. 1980), EPO was evaluated in nineteen patients with RA. The dose selected was $700 \mathrm{mg}$ oil containing $700 \mathrm{mg}$ linoleic acid and $70 \mathrm{mg}$ GLA/kg daily. We now know that this dose is unlikely to produce benefit, and indeed this study was negative. In another study by Hansen et al. (1983), there was a trend towards improvement in the EPO group, despite a lower dosage regimen being utilized. In both these studies, the time period evaluated was only 3 months, and it is likely that a minimum of 4-6 months is required for therapeutic benefit to become apparent. A further problem in the RA studies is the selection of an active placebo. One study (Brzeski et al. 1991) evaluated forty RA patients by giving a 6-month treatment of either EPO or placebo. Disappointingly, however, the placebo selected was olive oil, which may also have anti-inflammatory effects. Unsurprisingly, therefore, there were significant results in both groups. The EPO group showed an improvement in morning stiffness and a trend towards decreased articular index. In the placebo (olive oil) group, there was a significant reduction in articular index and a trend towards reduced morning stiffness. Furthermore, between 40 and $50 \%$ of the patients studied were receiving second-line therapy for their RA. The mechanism of action of a number of second-line agents may be mediated partially through PG and LT production, and it is thus inappropriate to evaluate these patients when only a modest dose of GLA supplementation is given ( $540 \mathrm{mg}$ GLA/d). In our own study (Belch et al. 1988), we treated the patients for 12 months (with a 3-month placebo wash-out phase) and used liquid paraffin as the placebo. We excluded patients requiring second-line therapy. We were able to show a decreased requirement for non-steroidal anti-inflammatory drug therapy which was statistically significant in subjects being given twelve capsules of EPO ( $540 \mathrm{mg} \mathrm{GLA}$ ), or an EPO-fish oil mix (450 mg GLA, $240 \mathrm{mg}$ EPA) daily compared with the placebo group (Fig. 4). The placebo, liquid paraffin, allowed us to attenuate what is normally a considerable placebo effect in this group of subjects. Unfortunately, with higher doses of EFA currently being studied (Zurier et al. 1996), liquid paraffin as a placebo is not appropriate due to effects such as diarrhoea. The problem of an active placebo is a very real one. In our study of the effects of fish oil in patients with RA (Lau et al. 1993b), our placebo was air-filled capsules. At the end of the study we contacted all patients by letter and only one of the thirty
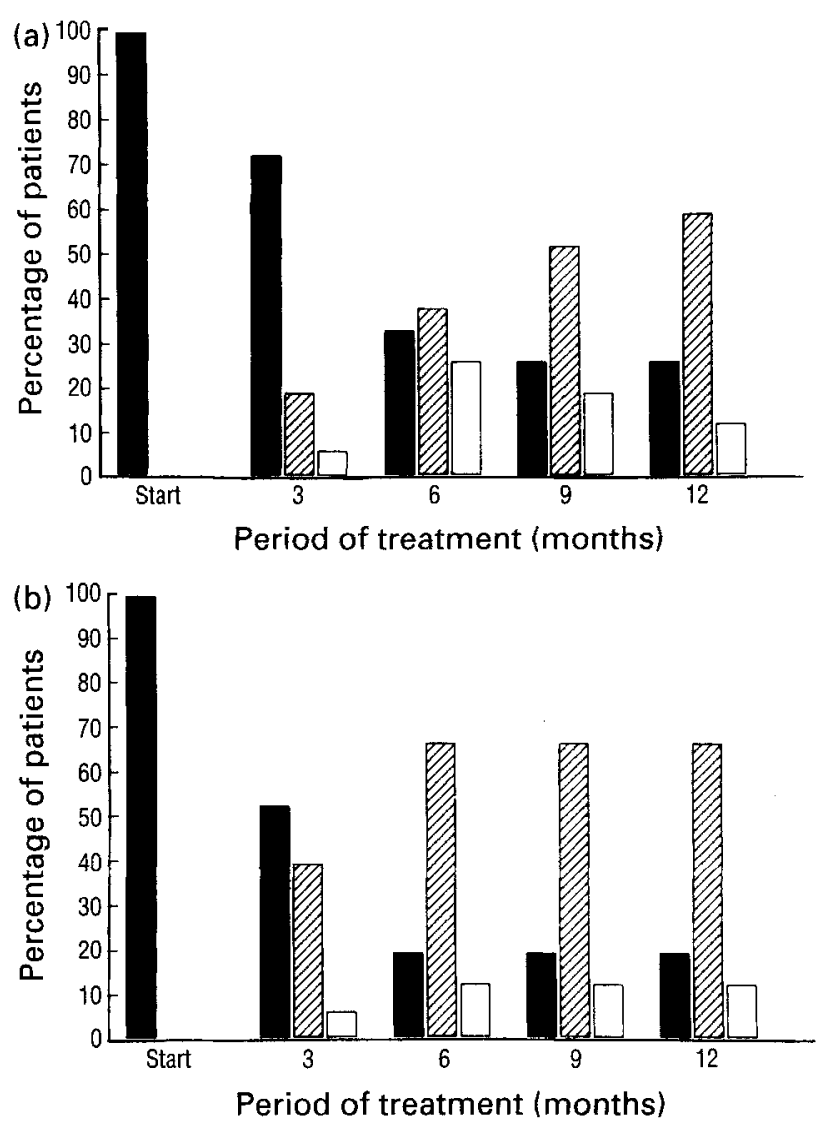

Fig. 4. Change in non-steroidal anti-inflammatory drug requirements $((\square)$, full dose; (שd), reduced dose) in placebo $\square)$, evening primrose (Oenothera biennis) oil (EPO; a) and EPO - fish oil (b) groups over 12 months. Subjects received twelve capsules of EPO (540 mg $\gamma$-linolenic acid) or an EPO - fish oil mix (450 $\mathrm{mg} \gamma$-linolenic acid, $240 \mathrm{mg}$ eicosapentaenoic acid). The placebo was liquid paraffin. (From Belch et al. 1988.)

placebo subjects had realised they were taking empty capsules. Hence, a placebo like this one might be a more appropriate choice for future studies, although it must be remembered that it will not provide any energy, unlike the active treatment. Other alternatives might include the recently-registered non-absorbable fat, but again this would not have the same energy value as the active treatment. Encapsulation of the saturated fat content from a standard national diet may be used. The problem with this latter selection would be an increase in saturated fat intake which might be unethical (Endres et al. 1995).

A recent study has evaluated a higher dose of GLA ( $2.8 \mathrm{~g}$ GLA as the free fatty acid/d) against a sunflower-seed-oil placebo (Zurier et al. 1996). This treatment resulted in a statistically significant reduction in the signs and symptoms of RA disease activity. Fifty-six patients received the 6-month course of either GLA or placebo, followed by a single-blind study of 6 months where all patients received GLA. During the second 6 months, both groups exhibited improvement in disease activity. The GLA doses used in this study were well tolerated. Further controlled studies of this dosage in RA are warranted. 


\section{n-3 Essential fatty acids and rheumatoid arthritis}

Early studies of EPA treatment in patients with RA show clinical improvement in the EPA-treated groups. In one study (Kremer et al. 1985) the decrease in joint tenderness was correlated with the decrease in PMN cell $\mathrm{LTB}_{4}$ production. Another study (Margaro et al. 1988) also showed a subjective alleviation of the symptoms of RA and reduction of neutrophil chemiluminescence after EPA supplementation. A further study (Geusens et al. 1994) confirmed that daily supplementation with $2.6 \mathrm{~g} \mathrm{n}$-3 EFA produced a significant clinical benefit, and this group also found a reduction in the requirement for concomitant anti-rheumatic medication. In our own studies, as mentioned previously (Belch et al. 1988), the mixture of EPO and EPA was also effective in decreasing non-steroidal anti-inflammatory drug usage over the 12-month study period (Fig. 5). At the time, we were uncertain whether the benefits obtained were due to the $n-6 \mathrm{EFA}$ within the treatment or to the fish oil. A placebo-controlled study investigating the effects of EPA-docosahexaenoic acid (Maxepa; Seven Seas Ltd., Kingston upon Hull, Humberside) therapy on non-steroidal anti- inflammatory drug usage in RA was carried out (Lau et al. 1993b). This study supports an effect independent of $n-6 \mathrm{EFA}$, with the patients on active treatment decreasing their daily dose of non-steroidal anti-inflammatory drugs.

\section{Issues for the future}

In reviews of EFA treatment for RA, it has been noted that the clinical benefits appear modest. This has led to the suggestion that EFA modification may not be a treatment worth following in RA and other rheumatological conditions. It must be appreciated, however, that when these studies were conceived and carried out, the sophisticated signalling and immunological data presented earlier in this symposium were not available to the study design. Whilst it was known that earlier dosage schedules were probably too low (Brown et al. 1980; Hansen et al. 1983), it was only later that treatment programmes extended past 3 months. We now know that peak clinical effects seem to occur between 6 and 9 months following the start of supplementation. Similarly, cross-over design is not appropriate due to the persistence of clinical effects and cell membrane fatty acids 3-4 months following treatment cessation (Fig. 6). A further study (Kremer et al. 1985) showed clear benefits in a new number of measures of disease activity before and after the first EFA treatment phase, but not between groups because of the cross-over design of their study.

Furthermore, in the 1980s the incomplete understanding of the mechanisms led some workers to select an 'active' control (Brzeski et al. 1991). Olive oil rich in oleic acid is now known to have potent effects as an immune modulator, but this was often selected as a study's placebo and led to difficulty in publishing the study results (G Darlington, personal communication).

With the ability to formulate EFA treatments of increased strength combined with the improvement of clinical trial design, the future study of these diseases should prove interesting.

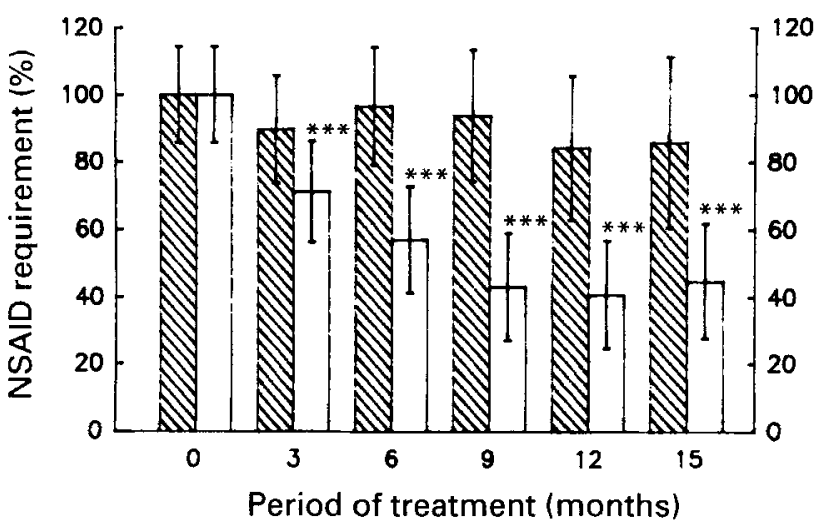

Fig. 5. Change in non-steroidal anti-inflammatory drug (NSAID) requirements in placebo (rza) and Maxepa (eicosapentaenoic acid-docosahexaenoic acid; Seven Seas Ltd., Kingston-upon-Hull, Humberside; $\square$ ) groups over 15 months (last 3 months both received placebo). Values are means and $95 \% \mathrm{Cl}$ represented by vertical bars. Mean values were significantly different from those before treatment (ANOVA): ${ }^{\star \star *} P<0.001$. (From Lau et al. 1993b.)

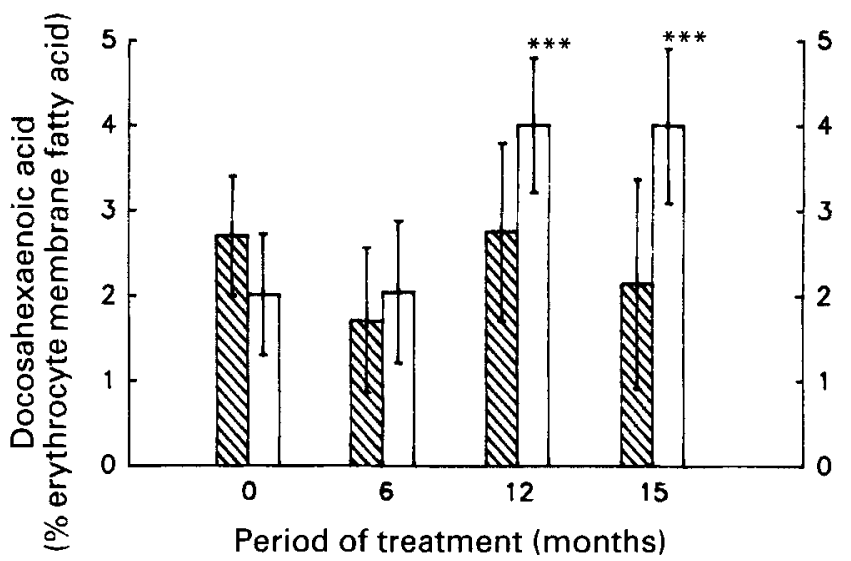

Fig. 6. Docosahexaenoic acid levels in erythrocyte membranes of patients receiving Maxepa (eicosapentaenoic acid-docosahexaenoic acid; Seven Seas Ltd., Kingston-upon-Hull, Humberside; $\square$ ) or placebo capsules (ma) over 15 months (last 3 months both received placebo). Persistent levels after 3 months of placebo were observed in the active (Maxepa) group. Values are means and $95 \%$ $\mathrm{Cl}$ represented by vertical bars. Mean values were significantly different from those before treatment (ANOVA): ${ }^{\star \star *} P<0.001$. (From Lau et al. 1993b.)

\section{Conclusion}

Dietary manipulation of EFA or supplementation with therapeutic doses may be effective as a treatment for rheumatological diseases (Hauben, 1993; Joe \& Hart, 1993). The assessment of their effects is, however, poorly studied to date, with inconclusive results, particularly in the field of Raynaud's phenomenon and Sjögren's syndrome. More convincing evidence exists in support of EFA usage in RA. A recently published study (Zurier et al. 1996) where a higher dose of GLA was evaluated is particularly interesting. The possibility that in the near future a new family of EFA anti-rheumatic drugs will be available is certainly not imaginary. However, this is entirely dependent on completion of well-designed clinical studies which are double-blind, contain parallel groups, have adequate power, and do not use an active placebo. 


\section{Acknowledgements}

The studies of rheumatoid arthritis carried out by the authors' own group were supported by the Arthritis and Rheumatism Council, UK. The authors would like to thank Scotia Pharmaceuticals (Stirling, Scotland) and Seven Seas Ltd. (Kingston upon Hull, Humberside) for the provision of the Efamol and Maxepa capsules respectively.

\section{References}

Belch JJF (1988) The role of eicosanoids in inflammation. In Immunopathogenic Mechanisms of Arthritis, pp. 26-50 [J Goodacre and WC Dick, editors]. Lancaster: MTP Press Ltd.

Belch JJF (1989) Eicosanoids and rheumatology: Inflammatory and vascular aspects. Prostaglandins, Leukotrienes and Essential Fatty Acids 36, 219-234.

Belch JJF (1995) Temperature related disorders. In Textbook of Vascular Medicine, pp. 329-352 [J Tooke and GDO Lowe, editors]. London: Edward Amold.

Belch JJF, Ansell D, Madhok R, O'Dowd A \& Sturrock RD (1988) Effects of altering dietary essential fatty acids on requirements for non-steroidal anti-inflammatory drugs in patients with rheumatoid arthritis: A double blind placebo controlled study. Annals of the Rheumatic Diseases 47, 96-104.

Belch JJF, McLaren M, Anderson J, Lowe GDO, Sturrock RD, Capell HA \& Forbes CD (1985a) Increased prostacyclin metabolites and decreased red cell deformability in patients with systemic sclerosis and Raynaud's syndrome. Prostaglandins, Leukotrienes and Medicine 17, 1-9.

Belch JJF, Shaw B, O'Dowd A, Curran L, Forbes CD \& Sturrock RD (1996) Evening primrose oil (Efamol) as a treatment of cold-induced vasospasm (Raynaud's phenomenon). Progress in Lipid Research 25, 335-340.

Belch JJF, Shaw B, O'Dowd A, Saniabadi A, Leiberman P, Sturrock RD \& Forbes CD (1985b) Evening primrose oil (Efamol) in the treatment of Raynaud's Phenomenon: A double blind study. Thrombosis and Haemostasis 54, 490-494.

Brown J, Sim AK, De Ceular K, McLeod M, El-Ghobarey AF \& Dick WC (1980) Naudicelle in patients with rheumatoid arthritis. Thérapeutique 50, 355-357.

Brzeski M, Madhok R \& Capell HA (1991) Evening primrose oil in patients with rheumatoid arthritis and side-effects of nonsteroidal anti-inflammatory drugs. British Journal of Rheumatology 30, 370-372.

Di Giacomo RA, Joel M, Kremer JM, Dhiraj M \& Shah DM (1989) Fish-oil dietary supplementation in patients with Raynaud's phenomenon: A double-blind, controlled, prospective study. American Joumal of Medicine 86, 158-164.

Endres S, De Caterina R, Schmidt EB \& Kristensen SD (1995) n-3 Polyunsaturated fatty acids: update 1995. European Journal of Clinical Investigation 25, 629-638.

Geusens P, Wouters C, Nijs J, Jiang Y \& Dequeker J (1994) Long-term effect of omega-3 fatty acid supplementation in active rheumatoid arthritis. A 12 month, double blind, controlled study. Arthritis and Rheumatism 37, 824-829.

Hansen TM, Lerche A, Kassis V, Lorenzen I \& Sondergaard J (1983) Treatment of rheumatoid arthritis with prostaglandin $E_{1}$ precursors cis-linoleic acid and gamma-linolenic acid. Scandinavian Journal of Rheumatology 12, 85-88.

Hauben M (1993) Evening primrose oil in the treatment of rheumatoid arthritis - proper application of statistical analysis. Comment. Annals of Pharmacotherapy 27, 1475-1477.

Horrobin DF (1984) Essential fatty acid metabolism in diseases of connective tissue with special reference to scleroderma and to Sjögren's syndrome. Medical Hypothesis 14, 233-271.
Horrobin DF (1991) Interactions between n-3 and n-6 essential fatty acids (EFAs) in the regulation of cardiovascular disorders and inflammation. Prostaglandins, Leukotrienes and Essential Fatty Acids 44, 127-131.

Hughes GRV (1994) Connective Tissue Diseases, 4th ed., pp. 102-104. Oxford: Blackwell Scientific Publications.

Jantti J, Nikkari T, Solskivi T, Vapaatalo H \& Isomaki H (1989) Evening primrose oil in rheumatoid arthritis: changes in serum lipids and fatty acids. Annals of the Rheumatic Diseases 48, $124-127$.

Joe LA \& Hart LL (1993) Evening primrose oil in rheumatoid arthritis. Annals of Pharmacotherapy 27, 1475-1477.

Kremer JM, Bigaouette J, Michalek AV, Lininger L, Huyck C, Timchalk MA, Rynes RI, Zeiminski J \& Bartholomew LE (1985) Effects of manipulation of dietary fatty acids on diurnal manifestation of rheumatoid arthritis. Lancet $\mathbf{i}, 184-187$.

Lau C, O'Dowd A \& Belch JJF (1992) White cell activation in the Raynaud's phenomenon of systemic sclerosis and vibration induced white finger syndrome. Annals of the Rheumatic Diseases 51, 249-252.

Lau CS, McLaren M, MacKay IR \& Belch JJF (1993a) Baseline plasma fibrinolysis and its correlation with clinical manifestations in patients with Raynaud's phenomenon. Annals of the Rheumatic Diseases 52, 443-448.

Lau CS, Morley KD \& Belch JJF (1993b) Effects of Maxepa fish oil supplementation on non-steroidal anti-inflammatory drug requirement in patients with mild rheumatoid arthritis. British Journal of Rheumatology 32, 982-989.

McLaren M, Lau C, Forbes CD \& Belch JJF (1990) Seasonal variation in fibrinolysis in patients with rheumatoid arthritis. Fibrinolysis 4, 116-117.

Magaro M, Altomonte L, Zoli A, Mirone L, De Sole P, Di Mario G, Lippa S \& Oradei A (1988) Influence of diet with different lipid composition on neutrophil chemiluminescence and disease activity in patients with rheumatoid arthritis. Annals of the Rheumatic Diseases 47, 793-796.

Manku MS, Morse N \& Belch JJF (1986) Effects of gammalinolenic acid supplementation on plasma essential fatty acids. Progress in Lipid Research 25, 469-473.

Manthorpe R, Hagen Petersen S \& Prause JU (1984) Primary Sjögren's syndrome treated with Efamol/Efavit. Rheumatology International 4, 165-167.

Maple C, McLaren M \& Belch JJF (1998) Dietary essential fatty acid supplementation with omega 3 and omega 6 fatty acids reduces whole blood white blood cell aggregation in healthy volunteers. Prostaglandins, Leukotrienes and Essential Fatty Acids (In the Press).

Mead CJ \& Mertin J (1978) Fatty acids and immunity. Advanced Lipid Research 16, 127-165.

Oxholm P, Manthorpe R, Prause JU \& Horrobin D (1986) Patients with primary Sjögren's syndrome treated for two months with evening primrose oil. Scandinavian Journal of Rheumatology 15 , 103-108.

Oxholm P, Pedersen BK \& Horrobin DF (1992) Natural killer cell functions are related to the cell membrane composition of essential fatty acids: differences in healthy persons and patients with primary Sjögren's syndrome. Clinical Experimental Rheumatology 10, 229-234.

Prescott SM, Zimmerman GA \& Morrison AR (1985) The effects of a diet rich in fish oil on human neutrophils: identification of leukotriene B5 as a metabolite. Prostaglandins 30, 209-227.

Rogers TJ (1985) The role of arachidonic acid metabolites in the function of murine suppressor cells. In Prostaglandins and Immunity, pp. 80-86 [JS Goodwin, editor]. Boston, MA: Martinus Nijhoff. 
Tziousas AG \& Moutsopoulos HM (1995) Sjogren's syndrome in connective tissue diseases. In Chapman \& Hall Medical, pp. 103-130 [JJF Belch and RB Zurier, editors]. London: Chapman \& Hall.

Veale DJ, Torley H, Richards IM, O’Dowd A, Fitzsimons C, Belch JJF \& Sturrock RD (1994) A double-blind placebo controlled trial of Efamol marine on skin and joint symptoms of psoriatic arthritis. British Journal of Rheumatology 33, 954-958.

Voorlees JJ (1983) Leukotrienes and other lipoxygenase products in the pathogenesis and therapy of psoriasis and other dermatoses. Archives of Dermatology 119, 541-547.

Weissmann G, Smolen JE \& Kirchak H (1980) Prostaglandins and inflammation: Receptor/cyclase coupling as an explanation of why PGEs and $\mathrm{PGI}_{2}$ inhibit functions of inflammatory cells. In Advanced Prostaglandin Thromboxane Research, pp. 1637-1638 [B Samuelsson, PW Ramwell and R Paoletti, editors]. New York: Raven Press.

Ziboh VA, Cohen KA, Charles EN, Miller C, Hamilton TA, Kragballe K, Hydrick CR \& Voorhees JJ (1986) Effects of dietary supplementation of fish oil on neutrophil and epidermal fatty acids. Modulation of clinical course of psoriatic subjects. Archives of Dermatology 122, 1277-1281.

Zurier RB, Rossetti RG, Jacobson EW, DeMarco DM, Liu NY, Temming JE, White BM \& Laposata M (1996) Gammalinolenic acid treatment of rheumatoid arthritis: A randomized, placebocontrolled trial. Arthritis and Rheumatism 39, 1808-1817. 